\title{
Interaction of 1,2-Diaminoimidazoles with Ethoxymythelene-Containing Compounds
}

\author{
Dmitry Yurievich Vandyshev ${ }^{*}$, Khidmet Safarovich Shikhaliyev and Andrey Yurievich Potapov \\ Faculty of Chemistry, Voronezh State University, Voronezh 394006, Russia
}

\begin{abstract}
Interaction of 1, 2-diaminoimidazole with ethoxymethylene-containing derivatives has been studied. It is determined that the interaction malondinitrile, cyanoacetic ester, acetylacetone leads to linearly linked products: 2-[[(2-amino-4-phenyl-1H-imidazole-1-yl)amino] methylene] propanedinitrile, ethyl ester 2-[(2-emino-4-phenyl-1H-imidazole-1-yl)amino]-2-cyano-2-propanoic acid and 2-[[(2-amino-4-phenyl-1H-imodazole-1-yl)amino] methylene]-2,4-pentanedoine. An exception is the reaction of ethoxymethylene ester, in the result of which 7-amino-2-methyl-5-phenyl-imidazol [1,5-b] pyridine-3-carboxylic acid ethyl ester is regioselectively formed. The products are obtained regardless of reaction condition. The structures of resulting compound are confirmed by NMR ${ }^{1} \mathrm{H}$ and mass spectroscopy. Further cyclization of linear intermediates with acetic acid, triethylamine, dimethylformamide and dioxane has led to asphaltization that implies difficulties of further individualize derived substances.
\end{abstract}

Key words: 1, 2-diamino-4-phenylimidazole, ethoxymethylenemalondinitrile, ethoxymythelenecyanoacetic ester, ethoxymethyleneacetylacetone, ethoxylacetoacetic ester, imidazopyridazines.

\section{Introduction}

Imidazole ring is a significant five-membered aromatic heterocycle presented in a great number of natural and synthetic substances. A unique structural feature allows it easily links with various enzymes and receptors in the biological systems [1]. That is exactly why developments of design and simplification of synthesis new heterocyclic structures on the imidazole basis, which would have directed action, have rapidly grown in medical chemistry [1-3]. Among the majority of condensed systems based on imidazole, special attention is paid to imidazopyridazine. These compounds have proven to be good anti-viral, anti-epileptic and anti-cancer drugs [2-12]. Imidazo[1,2-b]pyridazine and imodazo[1,5-b]pyridazine have a special place among possible variants of the system existence. What is more, the last-named is marginally studied.

A large amount of literature data reflect a various ways of this system design [6-11]. However many from this methods involve several steps including using hard-to-get reagents. This is way methods when using imidazoles derivatives are the most promising, in particular, 1, 2-diaminoimidazoles unsubstituted on carbon in the fifth position.

Previously it was described interaction ethoxymethylene-containing compounds with 4-substituted 2-amino-1-benzaliden (isopropylidene) of aminoimidazoles leading to imidazo[1,2-a]pyrimidines formation. The reaction was performed in acetonitrile with acid or basis catalyst [12]. However this reaction was not extended to 1,2-diaminoimidazoles unsubstituted on carbon in the fifth position.

The article is concerned with studying of 4-phenyl-1,2-diaminoimidazole interaction with ethoxymethylene derivatives with the aim of imidazo[1,5-b]pyridazine systems formation.

\footnotetext{
*Corresponding author: Dmitry Yurievich Vandyshev, Ph.D., research field: chemistry of heterocyclic compounds.
} 


\section{Experimental}

\subsection{Characterization}

NMR (Nuclear Magnetic Resonance) Spectra of all new compounds were registered on Bruker DRX, 500 ${ }^{1} \mathrm{H}$ spectrometer at $500 \mathrm{MHz}$ and in DMSO-d6, internal standard is TMS. Mass-spectra recorder on FINNIGAN MAT. INCOS 50 spectrometer (EI ionization, $70 \mathrm{eV}$ ). Elemental analyses was performed on Carlo Erba NA 1500.

Melting points was determined on Stuart SMP30. Identity of the reagents and synthesized compounds, quality of reaction mass were controlled out by TLC on Merck TLC Silica gel $60 \mathrm{~F}_{254}$ plate; eluents: methanol, chlorophorm and its mixture in the different rations. Chromatograms were developed in the UV light and iodine vapour.

2.2 General Method for the Synthesis of 2-[[(2-Amino-4-Phenyl-1H-Imidazole-1-yl)Amino] Methylene] Propanedinitrile 6

The mixture of $0.87 \mathrm{~g}(5 \mathrm{mmol})$ diaminoimidazole $1,0.67 \mathrm{~g}$ (5 mmol) ethoxymethylenemalondinitrile 2 , $5 \mathrm{~mL}$ of isopropyl alcohol and 1-2 drops of acetic acid was refluxed for 1-2 $\mathrm{h}$. The resulted precipitate was filtrated and recrystallized from mixture of 2-PrOH-DMFA, 2:1. A yellow powdery compound 6 was obtained.

Yield $70 \%$ mp 193-194 ${ }^{\circ} \mathrm{C}$. MS (EI, $\left.70 \mathrm{ev}\right), m / z, \%$ : $250\left[\mathrm{M}^{+}\right]$. NMR ${ }^{1} \mathrm{H}(500 \mathrm{MHz}, \mathrm{DMSO}-\mathrm{d} 6): \delta=6.05$ $\left(2 \mathrm{H}, \mathrm{s}, \mathrm{NH}_{2}\right) ; 7.34$ (1H, t, J = 7.4, p-H Ph); 7.45 (2H, d, $\mathrm{J}=7.8, \mathrm{~m}-\mathrm{H} \mathrm{Ph}) ; 7.66(1 \mathrm{H}, \mathrm{s}, \mathrm{CH}$-imidaz); $7.71(2 \mathrm{H}$, d, J-7.7, o-H Ph); 8.45 (1H, s, CH); 12.64 (1H, s, NH). Analysis: cal. for $\mathrm{C}_{13} \mathrm{H}_{10} \mathrm{~N}_{6}$ : C 62.39; H 4.03; N 33.58 . Found, \%: C 62.03; H 4.05; N 33.52.

2.3 General Method for the Synthesis of Ethyl Ester 2-[(2-Amino-4-Phenyl-1H-Imidazole-1-yl)Amino]-2-C yano-2-Propanoic Acid 7.

The mixture of $0.87 \mathrm{~g}(5 \mathrm{mmol})$ diaminoimidazole 1, $0.91 \mathrm{~g}$ (5 mmol) ethoxymethylenecyaneacetic ester
3, $5 \mathrm{~mL}$ of isopropyl alcohol and 1-2 drops of acetic acid was refluxed for 1-2 h. The resulted precipitate was filtrated and recrystallized from mixture of 2-PrOH-DMFA, 2:1. A light yellow powdery compound 7 was obtained.

Yield $85 \%$ mp 218-219 ${ }^{\circ} \mathrm{C}$. MS (EI, $70 \mathrm{ev),} m / z, \%$ : $297\left[\mathrm{M}^{+}\right]$. NMR ${ }^{1} \mathrm{H}(500 \mathrm{MHz}$, DMSO-d6): $\delta=1.29$ $\left(3 \mathrm{H}, \mathrm{t}, \mathrm{J}=7.1, \mathrm{CH}_{3}\right) ; 4.27\left(2 \mathrm{H}, \mathrm{q}, \mathrm{J}=7.1, \mathrm{CH}_{2}\right) ; 6.16$ $\left(1 \mathrm{H}, \mathrm{s}, \mathrm{NH}_{2}\right) ; 7.20(1 \mathrm{H}, \mathrm{t}, \mathrm{J}=7.4, \mathrm{p}-\mathrm{H} \mathrm{Ph}) ; 7.34(2 \mathrm{H}, \mathrm{t}$, $\mathrm{J}=7.8, \mathrm{~m}-\mathrm{H} \mathrm{Ph}) ; 7.54$ (1H, d, J = 7.6, o-H Ph); 8.37 $(1 \mathrm{H}, \mathrm{d}, \mathrm{J}=13.2, \mathrm{CH}) ; 11.2(1 \mathrm{H}, \mathrm{d}, \mathrm{J}=13.3, \mathrm{NH})$. Analysis: cal. for $\mathrm{C}_{15} \mathrm{H}_{15} \mathrm{~N}_{5} \mathrm{O}_{2}$ : C 60.60; $\mathrm{H}$ 5.09; $\mathrm{N}$ 23.55. Found, \%: C 61.00; H 5.06; N 23.59.

\subsection{General Method for the Synthesis of 2-[[(2-Amino-4-Phenyl-1H-Imodazole-1-yl)Amino] Methylene]-2,4-Pentanedoine 8.}

The mixture of $0.87 \mathrm{~g}(5 \mathrm{mmol})$ diaminoimidazole 1, $0.84 \mathrm{~g}$ (5 mmol) ethoxymethyleneacetylacetone 4, 5 $\mathrm{mL}$ of isopropyl alcohol and 1-2 drops of acetic acid was refluxed for 1-2 h. The resulted precipitate was filtrated and recrystallized from mixture of 2-PrOH-DMFA, 2:1. A yellow powdery compound 8 was obtained.

Yield $65 \%$. mp 196-197 ${ }^{\circ} \mathrm{C}$. MS (EI, $\left.70 \mathrm{ev}\right), m / z, \%$ : $284\left[\mathrm{M}^{+}\right]$. NMR ${ }^{1} \mathrm{H}(500 \mathrm{MHz}$, DMSO-d6): $\delta=2.38$ $\left(3 \mathrm{H}, \mathrm{s}, \mathrm{CH}_{3}\right) ; 2.43\left(3 \mathrm{H}, \mathrm{s}, \mathrm{CH}_{3}\right) ; 6.17\left(2 \mathrm{H}, \mathrm{s}, \mathrm{NH}_{2}\right)$; $7.20(1 \mathrm{H}, \mathrm{t}, \mathrm{J}=7.3$, p-H Ph); $7.35(2 \mathrm{H}, \mathrm{t}, \mathrm{J}=7.8, \mathrm{~m}-\mathrm{H}$ $\mathrm{Ph}) ; 7.55$ (1H, s, CH imidaz); $7.78(2 \mathrm{H}, \mathrm{d}, \mathrm{J}=7.0$, o-H $\mathrm{Ph}) ; 8.61(1 \mathrm{H}, \mathrm{d}, \mathrm{J}=12.5, \mathrm{CH}) ; 12.74(1 \mathrm{H}, \mathrm{d}, \mathrm{J}=12.5$, $\mathrm{NH})$. Analysis: cal. for $\mathrm{C}_{15} \mathrm{H}_{16} \mathrm{~N}_{4} \mathrm{O}_{2}$ : C 63.37; H 5.67; N 19.71. Found, \%: C 62.97; H 5.64; N 19.67.

\subsection{General Method for the Synthesis of Ethyl Ester} 7-Amino-2-Methyl-5-Phenylmidazo[1,5-b]Pyridazine3-Carbonic Acid 10.

The mixture of $0.87 \mathrm{~g}(5 \mathrm{mmol})$ diaminoimidazole 1, $0.99 \mathrm{~g}$ (5 mmol) ethoxymethyleneacetylacetone 4, 5 $\mathrm{mL}$ of isopropyl alcohol and 1-2 drops of acetic acid was refluxed for 1-2 $\mathrm{h}$. The resulted precipitate was filtrated and recrystallized from mixture of 
2-PrOH-DMFA, 2:1. A red powdery compound 10 was obtained.

Yield $95 \%$ mp 179-180 C. MS (EI, $70 \mathrm{ev),} \mathrm{m} / \mathrm{z}, \%$ : $296\left[\mathrm{M}^{+}\right]$. NMR ${ }^{1} \mathrm{H}(500 \mathrm{MHz}, \mathrm{DMSO}-\mathrm{d} 6): \delta=1.30$ $\left(3 \mathrm{H}, \mathrm{t}, \mathrm{J}=7.1, \mathrm{CH}_{2} \underline{\mathrm{CH}}_{3}\right) ; 2.45\left(3 \mathrm{H}, \mathrm{s}, \mathrm{CH}_{3}\right) ; 4.25(2 \mathrm{H}$, $\left.\mathrm{q}, \mathrm{J}=7.1, \underline{\mathrm{CH}_{2}} \mathrm{CH}_{3}\right) ; 6.56\left(2 \mathrm{H}, \mathrm{s}, \mathrm{NH}_{2}\right) ; 7.37-7.45(3 \mathrm{H}$, $\mathrm{m}, \mathrm{H} \mathrm{Ph}) ; 7.54$ (2H, dt, J = 6.8, J=1.6, o-H Ph); 8.24 (1H, s, CH-piridaz). Analysis: cal. for $\mathrm{C}_{16} \mathrm{H}_{16} \mathrm{~N}_{4} \mathrm{O}_{2}: \mathrm{C}$ 64.85; H 5.44; N 18.91. Found, \%: C 65.12; H 5.41; N 18.95 .

\section{Results and Discussion}

\subsection{Synthesis and Characterization}

As a polynucleophilic agent (1,3-C,N and 1,4-N,N) diaminoimidazole can form six- and seven-membered systems in the reaction with dielectrophilic agents. The determinative factor in the reaction direction are electrophile nature and conditions in which synthesis was performed [12-16].

The heterocyclization reaction of diaminoimidazole 1 with ethoxymethylene derivatives 2-5 was performed by refluxing in isopropyl alcohol in the presence of catalytic amount of acetic acid for 1-2 $h$ (Fig. 1). Yellow linearly linked products were isolated in the result of 2-4 reaction. According to $\mathrm{NMR}{ }^{1} \mathrm{H}$ spectroscopy they were assigned the structures of 6-8. Attempts to perform this interaction with others solvent, such as acetonitrile, acetic acid, dimethylformaide, dioxane, as well as cyclization of intermediates; led to hard separable uncrystallizable mixtures.

However, in the case of ethoxymethyleneacetoacetic ester a crystalline bright red substance was isolated to which it were assigned

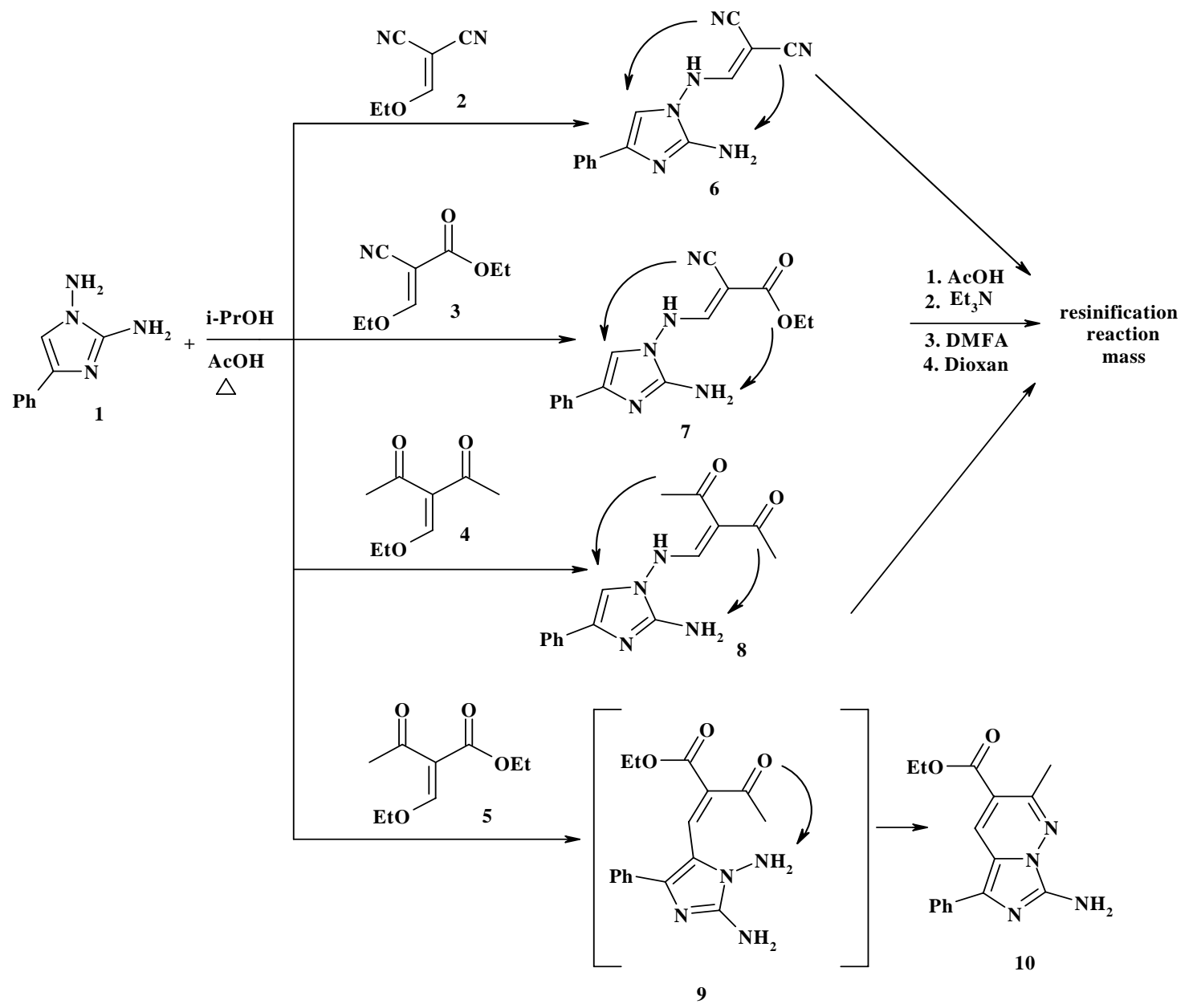

Fig. 1 The reaction of 1,2-diaminoimidazole with ethoxymethylene derivatives. 
structure

of

7-amino-2-methyl-5-phenyl-imidazol[1,5-b]

pyridazine-3-carboxylic acid 10 by NMR ${ }^{1} \mathrm{H}$ spectra and literature data.

At NMR ${ }^{1} \mathrm{H}$ spectra analysis of 6-8 structures it was noted formation of new $\mathrm{NH}$ proton doublets at 11.2-12.8 ppm and methylene fragment proton at 8.4-8.6 ppm. An extant singlet of imidazole cycle proton at C-5 (7.2 ppm) and doublet signals $\mathrm{NH}_{2}(6.2$ ppm) group allows to affirm about liner structures ofthe compounds.

NMR ${ }^{1} \mathrm{H}$ spectrum analysis of 10 shows that there are no imidazole cycle and amino group of hydrazine moiety protons signals. Instead, proton signal of pyridazine cycle at 8.25 was formed. The presence in the spectrum 10 two protons singlet of amino group allows to unambiguously stating six-membered system formation.

\section{Conclusions}

Thus, interaction of 1,2-diamino-4-phenylimidazole with oxymethyleneacetylacetone, methoxymethylene cyanoacetic ester and ethoxymethylenemalonodinitrile leads to formation of 2-[[(2-amino-4-phenyl-1H-imidazole-1-yl)amino]met hylene]-2,4-pentanedione, ethyl ester of 2 [(2-amino-4-phenyl-1H-imidazol-1-yl) amino] -2-cyano-2-propanoic acid, 2-[[(2-amino-4-phenyl-1H-imidazol-1-yl) amino] methylene]propanedinitrile respectively. The present compounds are not then cyclized. Ethyl ester of 7-amino-2-methyl-5-phenylimidazo[1,5-b]pyridazine3-carbonic acid is regioselectively isolated when using methoxymethyleneacetoacetic ester.

\section{Acknowledgments}

The results obtained in the framework of the work on the RF Government Resolution № 218 contract N 02.G25.31.0007 supported by the Ministry of Education and Science of the Russian Federation.

\section{References}

[1] Zhang, L., Peng, X-M., Damu, G. L. V., Geng, R-X. and Zhou, C-H. 2013. "Comprehensive Review in Current Developments of Imidazole-Based Medicinal Chemistry." Medicinal Research Reviews 34 (2): 340-437.

[2] Huang, W-S., Metcalf, C. A., Sundaramoorthi, R., Wang, Y., Zou, D. and Thomas, R. M. et al. 2010. "Discovery of 3-[2-(Imidazo[1,2-b]Pyridazin-3-yl)Ethynyl]-4-Methyl-N - \{4-[(4-Methylpiperazin-1-yl)-Methyl]-3-(Trifluoromethy 1)Phenyl B Benzamide (AP24534), a Potent, Orally Active Pan-Inhibitor of Breakpoint Cluster Region-Abelson (BCR-ABL) Kinase Including the T315I Gatekeeper Mutant." J. Med. Chem. 53: 4701-19.

[3] Peterson, E. A., Boezio, A. A., Andrews, P. S., Boezio, C. M., Bush, T. L. and Cheng, A. C. et al. 2012. "Discovery and Optimization of Potent and Selective Imidazopyridine and Imidazopyridazine mTOR Inhibitors." Bioorganic Medicinal Chemistry Letters 22: 4967-74.

[4] Miller, G. D., Woessner, D. W., Sirch, M. J. and Lim, C. S. 2013. "Multidomain Targeting of Bcr-Abl by Disruption of Oligomerization and Tyrosine Kinase Inhibition: Toward Eradication of CML." Mol. Pharmaceutics 10: 3475-83.

[5] Foulks, J. M., Carpenter, K. J., Luo, B., Xu, Y., Senina, A and Nix, R. et al. 2014. "A Small-Molecule Inhibitor of PIM Kinases as a Potential Treatment for Urothelial Carcinomas." Neoplasia 16: 403-12.

[6] Moreau, S., Coudert, P., Rubat, C., Vallee-Goyet, D., Gardette, D. and Gramain, J-C. et al. 1998. "Synthesis and Anticonvulsant Properties of Triazolo- and Imidazopyridazinyl Carboxamides and Carboxylic Acids." Bioorganic Medicinal Chemistry 6: 983-91.

[7] Rimoli, M. G., Russo, E., Cataldi, M., Citraro, R., Ambrosino, P. and Melisi, D. et al. 2009. "T-Type Channel Blocking Properties and Antiabsence Activity of Two Imidazo [1, 2-b] Pyridazine Derivatives Structurally Related to Indomethacin." Neuropharmacology 56: 637-46.

[8] Chapman, T. M., Osborne, S. A., Bouloc, N., Large, J. M., Wallace, C. and Birchall, K. et al. 2013. "Substituted Imidazopyridazines are Potent and Selective Inhibitors of Plasmodium Falciparum Calcium-Dependent Protein Kinase 1 (PfCDPK1)." Bioorganic Medicinal Chemistry Letters 23: 3064-9.

[9] Large, J. M., Osborne, S. A., Smiljanic-Hurley, E., Ansell, K. H., Jones, H. M. and Taylor, D. L. et al. 2013. "Imidazopyridazines as Potent Inhibitors of Plasmodium Falciparum Calcium-Dependent Protein Kinase 1 (PfCDPK1): Preparation and Evaluation of Pyrazole 
Linked Analogues.” Bioorganic \& Medicinal Chemistry Letters 23 (21): 6019-24.

[10] Roberts, L. R., Bradley, P. A., Bunnage, M. E., England, K. S., Fairman, D. and Fobian, Y. M. et al. 2011. "Acidic Triazoles as Soluble Guanylate Cyclase Stimulators." Bioorganic Medicinal Chemistry Letters 21: 6515-8.

[11] Livermore, D. G. H., Bethell, R.d C., Cammack, N., Hancock, A. P., Harm, M. M. and Green, D. V. S. et al. 1993. "Synthesis and Anti-HIV-1 Activity of a Series of Imidazo[1,5-b]Pyridazines.” J. Med. Chem. 36: 3784-94.

[12] Miyamoto, Y. 2002. "Synthesis of Nitrogen-Containing Heterocycles 10 [1]. Reaction of 2-Amino-1H-imidazole Derivatives with Etoxymethylene Compounds." $J$. Heterocyclic Chem. 39: 157-62.

[13] Lipson, V. V., Svetlichnaya, N. V., Shishkina, S. V. and Shishkin, O. V. 2008. "Cascade Cyclization of 1,
2-Diamino-4-Phenylimidazole with Aromatic Aldehydes and Meldrum's Acid." Mendeleev Commun 18: 141-3.

[14] Lipson, V. V., Svetlichnaya, N. V., Shirobokov, M. G., Musatov, V. I., Shishkin, O. V. and Shishkina, S. V. 2012. "Cascade Cyclization of 1,2-Diamino-4-Phenylimidazole with Aromatic Aldehydes and Cyclohexanediones." Russ. J. Org. Chem. 48: 273-7.

[15] Vandyshev, D. Yu., Shikhaliev, Kh. S., Potapov, A. Yu. and Krysin, M. Yu. 2014. "Cascade Two-and Three-Component Cyclization Reactions Using 1, 2-Diamino-4-Phenylimidazole and Cyclohexane-1, 3-Diones." Chem. Heterocycl. Compd. 50: 1316-21.

[16] Vandyshev, D. Yu., Shikalyev, Kh. S., Potapov, A. Yu. and Krysin, M. Yu. 2015. "A Novel Method for the Synthesis of Imidazo[1,5-b]Pyridazines." Chem. Heterocycl. Compd. 51: 573-7. 